\title{
DNR and COVID-19: The Ethical Dilemma and Suggested Solutions
}

\author{
Hala Sultan ${ }^{1 \dagger}$, Razan Mansour ${ }^{2 \dagger}$, Omar Shamieh ${ }^{3}$, Amal Al-Tabba' ${ }^{4}$ and \\ Maysa Al-Hussaini ${ }^{5 *}$
}

${ }^{1}$ School of Medicine, University of Jordan, Amman, Jordan, ${ }^{2}$ Outcomes and Implementation Research Unit, Department of Internal Medicine, University of Kansas Medical Center, Kansas City, MO, United States, ${ }^{3}$ Department of Palliative Care, King Hussein Cancer Center, Amman, Jordan, ${ }^{4}$ Independent Researcher, Amman, Jordan, ${ }^{5}$ Human Research Protection

Program, King Hussein Cancer Center, Amman, Jordan

\section{OPEN ACCESS}

Edited by:

Delia Boccia,

University of London, United Kingdom

Reviewed by:

David Hunter,

University of Adelaide, Australia

Paul Russell Ward,

Flinders University, Australia

*Correspondence:

Maysa Al-Hussaini

mhussaini@khcc.jo

tThese authors have contributed equally to this work

Specialty section: This article was submitted to

Public Health Policy, a section of the journal

Frontiers in Public Health

Received: 11 May 2020 Accepted: 19 March 2021

Published: 12 May 2021

Citation:

Sultan H, Mansour R, Shamieh O, Al-Tabba' A and Al-Hussaini M (2021)

DNR and COVID-19: The Ethical

Dilemma and Suggested Solutions.

Front. Public Health 9:560405.

doi: 10.3389/fpubh.2021.560405
Ethics are considered a basic aptitude in healthcare, and the capacity to handle ethical dilemmas in tough times calls for an adequate, responsible, and blame-free environment. While do-not-resuscitate (DNR) decisions are made in advance in certain medical situations, in particular in the setting of poor prognosis like in advanced oncology, the discussion of DNR in relation to acute medical conditions, the COVID-19 pandemic in this example, might impose ethical dilemmas to the patient and family, healthcare providers (HCPs) including physicians and nurses, and to the institution. The literature on DNR decisions in the more recent pandemics and outbreaks is scarce. DNR was only discussed amid the H1N1 influenza pandemic in 2009, with clear global recommendations. The unprecedented condition of the COVID-19 pandemic leaves healthcare systems worldwide confronting tough decisions. DNR has been implemented in some countries where the healthcare system is limited in capacity to admit, and thus intubating and resuscitating patients when needed is jeopardized. Some countries were forced to adopt a unilateral DNR policy for certain patient groups. Younger age was used as a discriminator in some, while general medical condition with anticipated good outcome was used in others. The ethical challenge of how to balance patient autonomy vs. beneficence, equality vs. equity, is a pressing concern. In the current difficult situation, when cases top 100 million globally and the death toll surges past 2.7 million, difficult decisions are to be made. Societal rather than individual benefits might prevail. Pre-hospital triaging of cases, engagement of other sectors including mental health specialists and religious scholars to support patients, families, and HCPs in the frontline might help in addressing the psychological stress these groups might encounter in addressing DNR in the current situation.

Keywords: COVID-19, do not resuscitate, ethics, healthcare, Pandemic

\section{INTRODUCTION}

Cardiopulmonary resuscitation (CPR) was first devised in 1530 (1). However, it was only in 1956 that CPR was reinvented and refined into the currently known and performed technique (2). Do-not-resuscitate (DNR) is defined when neither basic (heart compressions and ventilation) nor advanced (defibrillator or medicines) CPR should be performed. Terminally ill patients for which further medical intervention is considered futile, when quality of life is deemed poor, or 
who are expected to be permanently dependent on ventilators are the cases in which DNR is considered a plausible decision. The DNR decision is usually made based on a combination of the medical decisions and the patient's wishes and values. Interestingly though, the legal status of DNR varies between countries; from allowing it to a complete prohibition with legal consequences (personal communication). A link between ethics and DNR became a heated topic and the subject of published literature in 1979 (3), and later on addressed in further publications (4-8). Many linked religious and psychosocial conditions (9), and spirituality (10), as well as ethnicity (11) to the acceptance of the DNR order. Other features like chronic illness and old age may also impact the DNR decision (12-14), although a patient as young as 40 years old might succumb to the DNR order in the face of certain medical conditions (15). Children with DNR orders serve yet another example where physicians might encounter hardship as parents/ guardians have to make difficult decisions $(9,16)$. Also, more acute conditions within the setting of an intensive care unit (ICU) for example can elicit a DNR order (17). In the setting of lower-respiratory tract infection/pneumonia for example, DNR orders resulted in lower hospitalization and hospital-based mortality incidences suggesting that even in the absence of outbreaks and pandemics, planning and implementing DNR would save resources which can then be re-directed $(18,19)$.

Resources can become especially scarce during a pandemic. The World Health Organization (WHO) defines a pandemic as "the worldwide spread of a new disease" (20) where the R0, a term that reflects "how infectious a disease is," is $>1$ (21). In the more recent era, the world had witnessed many disease outbreaks, some of which were declared worldwide pandemics. These include, but are not limited to, the Asian flu in 1957, Severe acute respiratory syndrome (SARS) in 2002, Ebola in 2014, and lastly Zika in 2015 (22).

A thorough search affirmed that the closest recent pandemic to the current COVID-19 pandemic is H1N1 influenza (R0 $=1.4-1.6$ ). Back in 2009, the UK's Resuscitation Council established guidelines regarding $\mathrm{CPR}$ and the $\mathrm{H} 1 \mathrm{~N} 1$ influenza pandemic (22). It affirmed that DNR patients should be identified early on so that no CPR is attempted. However, in the case of commencement with $\mathrm{CPR}$, only chest compressions should be started; mouth-to-mouth ventilation should be avoided. Recently, an article on the American Heart Associations' guidance for CPR amid the COVID-19 pandemic reiterated the aforementioned $\mathrm{H} 1 \mathrm{~N} 1$ guidelines, and also emphasized the use of airborne infection isolation rooms especially when there is a risk of dissemination of virus droplets, such as endoscopies, and bronchoscopy procedures, as well as respiratory protection; most importantly an N95 mask (23). More importantly, physicians are recommended to intubate patients with respiratory failure owing to the COVID-19 virus to reduce the risk of aerosol generation (24). The current pandemic, owing to the pervasive COVID19 virus, with up to 100 million cases worldwide and 2,170,000 deaths (January 27, 2021), advocates for upfront implementation of the DNR order to COVID-19 infected patients; especially the elderly or those deemed associated with poor prognosis as per the physician's assessment (25). The inquiry here is multifaceted. How ethical is it to consider unilateral (i.e., without prior consent of patient) DNR orders for COVID19 infected patients in the face of limited resources? What are the potential consequences for other patients suffering from acute heart conditions, respiratory conditions, or road traffic accidents who might be competing with COVID-19 infected patients for the limited ventilators? Can we deny preplanned treatment management to certain groups of patients (like for example new and on-treatment cancer patients) to preserve needed ICU rooms and ventilators if unilateral DNR orders for COVID-19 infected cases could not be made? And essentially, what are the moral consequences for the healthcare providers (HCPs) making these tough decisions? How might these measures interject with the four major principles of medical ethics; autonomy, beneficence, non-maleficence, and justice? What would be a plausible approach to this ethical dilemma?

To address these questions, an exhaustive literature review using PubMed, Medline, Science Direct, and online news sites was undertaken to gather evidence and summarize the local, regional, and international recommendations.

How ethical is it to consider unilateral DNR orders for COVID-19 patients in the face of limited resources?

The answer to this question might not be straight forward. Given COVID-19's very high R0 as well as the relatively low success rate of CPR among ICU patients in general and the scarcity of personal protective equipment (PPE), many "hospitals on the frontline of the pandemic are attempting to weigh the costs of exposing doctors and nurses to the coronavirus" (26). On a global level, the issue is; what happens if HCPs who are at the frontline in our battle against COVID-19 get infected with the virus in an attempt to resuscitate a patient with a very low probability of survival, i.e., older people with preexisting comorbidities; including cardiac, respiratory, and other chronic health disorders (27)? It is also important to recall that the possibility of discharging an ICU patient after using CPR is around $17 \%$ (28), and that CPR is only effective in the first 4 to $7 \mathrm{~min}$ of cardiopulmonary arrest; by the time physicians reach the patient, especially if they had to wear PPE, they might have already run out of time. On the other hand, rushing to respond to CPR situations can increase the probability of PPE breach, putting HCPs at risk of infection (26). Moreover, most patients who are successfully resuscitated will need a ventilator, further contributing to the scarcity of resources amidst the COVID-19 pandemic, and possibly depriving other patients with a greater probability of survival from using these resources. In light of these debatable questions, DNR seems to be an immensely valid option.

An article by Curtis et al. (27), "Decisions About Do-NotResuscitate Orders During COVID-19," emphasizes the dangers of COVID-19 and that its spread has led to the development of so-called "unilateral DNR." This term was coined to "reduce the risk of medically futile CPR to patients, families, and healthcare workers." This is especially when CPR will unlikely allow successful return to an acceptable quality of life. It also saves ICU resources to allow for the accommodation of patients with a better chance of recovery. In the case that such protocols 
are implemented, all patients and family members should be knowledgeable about and adhere to the healthcare unit's wishes.

One such example is in New Jersey and some hospitals in New York; as of March 27, 2020, all "COVID-19 patients [will be placed] on a DNR-B resuscitation status." In DNR-B, all patients continue to receive their treatment for all medical conditions except in the event of a cardiac arrest (29), "No code blue will be called on any COVID-19 patients." (30) Other states in the United States, as well as other countries, are yet to decide.

A study in 2016 that addressed the ethicality of allocating scarce medical resources by HCPs explored the views of general practitioner (GP), medical students, and lay people (31). In one of the scenarios addressed (Scenario-B), allocation of scarce beds in hospitals amid an imaginary flu epidemic, lay personnel ranked the "sickest" patient as the priority in the limited bed allocation, while "prognosis" was top rated by the GP, medical students, and other HCPs. This clearly addressed the potential controversy that might arise among HCPs and patients during health crises like pandemics and that should be addressed in anticipation of any.

Whether patients infected with COVID-19 can be considered as a vulnerable population (people in need of special care, support, or protection because of age, disability, or risk of abuse or neglect) warrants further consideration while addressing the issue of DNR. Age was among the discriminator to triage patients; patients older than 80 years were offered DNR because of the futility of treatment and co-morbidities (25). Patients and families of patients diagnosed with COVID-19 disease have been stigmatized in some communities, which further adds to the vulnerability of COVID-19 patients (personal communication).

What are the potential consequences for other patients suffering from acute heart conditions, respiratory conditions, or road traffic accidents who might be competing with COVID-19 patients for the limited resources?

Triaging patients including COVID-19 patients, those with acute conditions like cardiopulmonary cases, those with emergency surgical intervention as well as cancer patients planned for elective surgeries which can be postponed for a maximum of a few weeks, but no longer, would be an important ethical consideration when addressing the potential of limited resources should ICUs and ventilators be needed. In Italy, around $50 \%$ of hospital beds in a 1,000-bed hospital in Northern Italy were occupied by COVID-19 patients (32), leaving the other half to deal with the rest of the other medical conditions, which might be sub-optimal to say the least. As a consequence, elective surgeries have been canceled, semielective procedures postponed, and operating rooms turned into makeshift ICUs (32).

The practice of dealing with DNR is sub-optimal even in the luxury of the routine practice outside pandemics. Within the setting of oncology practice in particular, Pettersson et al. reported that almost half of the nurses and physicians surveyed on the issue of DNR reported that "it is not likely that the patient would be involved in the decision on DNR," $21 \%$ believed that it is irrelevant to inform patients of the DNR decision, and $57 \%$ reported that providing information to the patient was important, although only $21 \%$ stated that this was likely to happen (33). Importantly, Bovman argues that reversing a

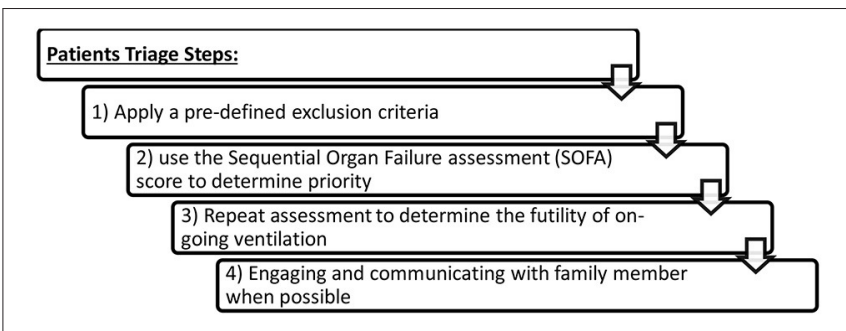

FIGURE 1 | Patient triage steps.

DNR code if elective surgery is warranted is associated with a dismal 30-day mortality (34). One important limitation is that patients treated for other conditions might end up infected with COVID-19 once admitted to the hospital (32).

At King Hussein Cancer Center (KHCC), the only standalone cancer center in Jordan, difficult decisions had to be made as well (35). During the months of March, April, and May, all elective surgeries, clinical appointments, and procedures were canceled, and chemotherapy and radiotherapy were canceled for the first two weeks and then started to build up gradually during the third week in anticipation of a potential surge of COVID-19 infected cases. In addition, patients were instructed to call a designated hotline if needed instead of in-person arrival to KHCC. A fully prepared ward was assigned to quarantine confirmed COVID-19 patients. All non-frontline employees were asked to stay at home, and a minimal number of HCPs were scheduled to cover the needs. Although this could compromise the small windows cancer patients might have, difficult decisions are made in anticipation of the worst (Ethical Considerations for Treating Cancer Patients during the SARS-COV-2 Virus Crisis: To Treat or Not to Treat? A Cancer Center in Low-Middle Income Country).

\section{What Are the Consequences for HCPs Taking These Tough Decisions?}

In harmony with the Hippocratic Oath, every medical physician swears to "apply, for the benefit of the sick, all measures [that] are required" (36). This regards not only to day-to-day practice, but also, and more importantly, for when they are needed most, such as in times of outbreaks. Accordingly, the consequences for the HCPs can be divided into physical/physiological and psychological/moral injuries.

To HCPs, and in accordance with what their degrees encompass, universal DNR to COVID-19 infected patients does not seem to be an option, adding to the ethical dilemma, selfblame, and burnout of the frontline decision makers. In some countries like the US, hospitals should apply for a so-called 1135 waiver, that waiver temporarily lifts Centers for Medicare \& Medicaid Services requirements in times of a national emergency, because failing to do so is considered "in violation of patient rights"(37). In a study that addressed frontline vs. non-frontline nurses dealing with COVID-19 patients, a significant difference in both physiology and psychology between both groups was in favor of frontline nurses (38). 


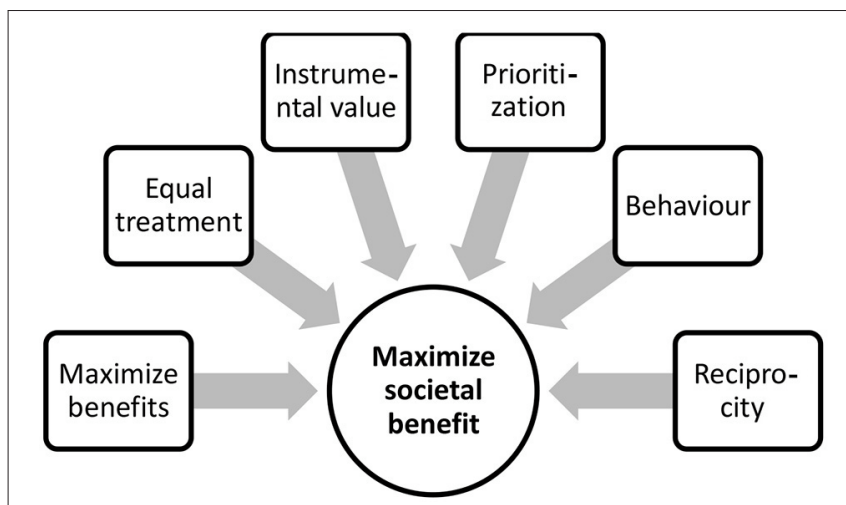

FIGURE 2 | A multi-value ethical framework to maximize societal benefit.

As for the psychological/moral consequences, in this particular setting of the COVID-19 pandemic, initiating or terminating a life supporting ventilator might be among the most difficult acts a physician can make during his/her career (39). Italian physicians were reported to weep in hospital hallways because of the difficult decisions they had to make (40).

It would be of interest to investigate if the HCPs in the current pandemic understand the burden of approving a DNR for patients infected by COVID-19. While this might be unreachable in the current condition, to understand the impact of the one-way tough decisions made by the physicians should be the subject of further research.

\section{How Might These Measures Interject With the Four Major Principles of Medical Ethics; Autonomy, Beneficence, Non-maleficence, and Justice?}

The dispute here is whether DNR codes, especially the unilateral DNR code, and resuscitation guidelines respect the four core medical ethics principles: autonomy, beneficence, nonmaleficence, and justice (41).

\section{Autonomy}

Autonomy and non-maleficence were reported by nurses and physicians, respectively, as the most important ethical values when dealing with the DNR status (42). Deciding on DNR on behalf of patients, i.e., unilateral DNR to save others with a higher probability of survival and to protect HCPs may serve the principles of equity and not equality, and seems to violate the principle of autonomy, which honors the patients' preference and wishes regarding any decision for their medical care. Fostering autonomy would dictate the discussion of all care-related options including the DNR code and do-not-operate (DNO) code with the patient and/or family so that they can make an informed decision (43-45). An informed consent form signed by the patient or a surrogate might, however, falsely re-assure the HCPs of the patient's understanding and thus volunteerism and autonomy (46). Also, making decisions on behalf of a competent patient exemplifies a paternalistic and professional nihilism that contradicts autonomy (47). Additionally, weighing the risk-tobenefit ratio and prioritizing societal over individual benefit is another issue when considering DNR, especially amid the COVID-19 pandemic.

\section{Justice}

The principle of justice entails "fair adjudication between conflicting claims," as well as treating patients with fairness, and to do so equally and equitably (48). Concerning the COVID-19 pandemic and DNR, the term "distributive justice" resurfaces, which considers fair allocation of resources, treatments, and benefits during a time of medical resource scarcity. Physicians started treating patients equitably but not equally, and other factors entered the equation when it came to providing care, as patients with the best chance of recovery were prioritized over others (49). Moreover, due to prolonged exposure, close contact, and lack of PPE, healthcare workers are at a significantly increased risk of acquiring infection (50), and should be prioritized when providing critical care when it comes to advanced life support.

What medical and ethical decision should be made when all patients are equal in need and predicted outcome, but the resources are barely enough? One study proposed a central "lottery" system as a solution for the distribution of resources to these patients. Patients' characteristics were suggested to be entered into the system and a supervised random selection process should then take place to ensure fair and equity of distribution (51). This could also apply to patients who are predicted to need CPR. However, the controversy will still be an issue, and there will be no single "best" answer.

\section{Beneficence and Non-maleficence}

Beneficence is defined as "an act of charity, mercy, and kindness with a strong connotation of doing good to others including moral obligation" (52). In healthcare, beneficence encompasses the idea that a physician's actions, decisions, and skills must always advocate for what is best for the patient. Physicians must apply the principle of beneficence while causing no harm to patients, a term referred to as non-maleficence ("above all do no harm"). In this instance, CPR is advised to be performed on patients if apparent benefit was the expected result. However, some argue that CPR should not be performed if it is not expected to result in benefit to patients, or if it may prolong their suffering, and the physicians should accordingly write a unilateral DNR order (53). The ethical and medical decision depends upon weighing therapeutic benefits against risks.

\section{What Would Be a Plausible Approach to the Ethical Dilemma?}

In a more conscious evaluation of the objective indications of DNR, Lipsky identified four core elements that can be assessed when deciding on DNR; futility of treatment, poor quality of life, patient refusal, and cost (54). If these same elements are applied into the current condition, where societal benefit prevails over self-benefit, it would be logical to consider any of the aforementioned four elements as a justification for the universal or unilateral DNR code adopted by the health sector 
in some nations. Along the same lines, Edwards B.S., argues that a small but significant number of ICU DNR-coded patients consume the already scarce resources including HCPs; nurses in this particular case within normal circumstances (55), let alone the current COVID-19 pandemic and the strain on limited resources. Calls for a just allocation for the use of the already limited resources are in place despite potential adverse effects on patient's autonomy and beneficence. Additionally, an important argument would be that an early DNR code would save the patient and family futile interventions (13). Triaging patients can be a multi-step and dynamic process that consists of three steps including (1) the application of exclusion criteria, (2) using the Sequential Organ Failure Assessment (SOFA) score to determine priority, and (3) repeated assessments to determine the futility of on-going ventilation (39). We would suggest a fourth point for engaging and communicating with family members when possible (Figure 1).

Curtis et al. shared an algorithm on how to address advanced care planning, the goals of care, and informed assent with a patient or surrogate family. This should proceed stepwise so that the patient and/or family surrogate can affirm understanding or are otherwise allowed to object (27). Since not one single ethical consideration might be able to address how to allocate scarce resources, a multi-value ethical framework, where more than one factor is considered, might seem more ethical (25). Maximizing benefits, i.e., saving the most lives and treating those with better prognosis, equal treatment to people, i.e., selection among people with similar prognosis, instrumental value, i.e., benefits to others, and priority to the sickest or the youngest when it aligns with maximizing benefits, should all be combined to maximize societal benefit. Additional factors that we suggest based on this literature review to help align scarce resources include behavioral status; priority to those who did not engage in risky behaviors that caused their condition or affected it negatively, and reciprocity; priority to those who have voluntarily provided societal services in the past (Figure 2).

Deployment of the medical workforce in areas in most need is an effective modality to support healthcare systems. This has been an effective strategy in Wuhan, China, where attempts to contain the spread of the pandemic was a wise decision (38). In the US, due to the likelihood of a shortage of HCPs, many retired physicians and medical students volunteered to aid in the crisis. Dr. Judy Salerno, a retired physician in her 60s declared that "if (she) can use (her) skills in some way that will be helpful, (she) will step up" (56). Medical students have also aided, taking basic histories over phone calls and babysitting for HCPs overwhelmed in hospitals and other facilities. In Jordan, medical students were heavily engaged with surveillance activity for potentially infected persons, as well as volunteering to deliver prescribed drugs to patients (personal communications).

The psychological impact on HCPs is of paramount importance (57), and should be accounted for when nationwide decisions are put in place (38). It is of value to note that whether or not a physician or hospital desires to commence with the unilateral DNR protocol, this decision should not be left entirely up to them; "providers, administrators, attorneys, clergy, and compliance" should be called to discuss the specifics (20). Proper training and education of the HCPs, especially junior staff, should be in place to help alleviate misconception on the timing of, and inclusion/exclusion criteria of the DNR code $(58,59)$. In addition, DNR needs to be disclosed by the more experienced members in the caring team (60). Many hospitals would triage CPR/DNR patients in the hand of a committee, none of the members of which are involved in patient treatment (39). One suggestion is to create a "triage committee" composed of senior and respected members of the medical community who volunteer to sit in on these committees, thus preventing first-line HCPs from making tough decisions that may impact their well-being. KHCC has adopted a similar approach, where the decision on unilateral DNR has to be made by a committee composed of the primary physician and two other physicians for terminally ill patients if a shortage in ventilators occurs in the future in Jordan (35).

An often overlooked facet is the role religious scholars can play when a DNR order is made. Religious scholars for different theistic groups should be made part of the clinical ethics committees in the hospitals, and in the case of the COVID-19 pandemic, national committees that address the DNR issue in acutely diseased and admitted infected patients (61). Providing support to the patient and/or family should also be extended after discussing the DNR. The presence of ethics-trained religious scholars can be of utmost importance especially when confronting national crises to ensure patient dignity, coping strategies for the family, and relief of the HCPs, with an ultimate goal to support family members as well as HCPs. Of interest, the European Islamic Jurisdiction Council clearly addressed the social impact on larger communities associated with the COVID-19 pandemic. Driven by the larger societal benefit, DNR orders were endorsed if deemed necessary by a compatible physician (62).

\section{CONCLUSION}

Despite the ethicality of this matter, and as a result of the rapid evolution and progress of the COVID-19 pandemic, as well as the anticipated shortage of resources, some hospitals have already made decisions. Public trust and confidence in the medical decision should not, however, be overlooked. Transparency of the medical sector, along with public engagement should help in alleviating the ethical burden of applying the unilateral DNR to COVID-19 infected patients and maintaining public trust. Practical approaches are suggested to address the potential sequelae. All in all, the question facing HCPs here may not precisely be how ethical, but rather: what choice do you make when 7.8 billion people's lives are at risk?

\section{AUTHOR CONTRIBUTIONS}

HS: literature review, writing the first draft, and review and final approval. RM: literature review, reviewing the first draft, and final review and approval. OS: literature review, critical review of the draft manuscript, and final review and approval. AA-T: literature review, reviewing the first draft, and final review and approval. MA-H: inception of the idea, literature review, critical review of the first draft, and final review and approval. All authors contributed to the article and approved the submitted version. 


\section{REFERENCES}

1. Association AH. CPR and First Aid. Emergnecy Cardiovascular Care [Teaching site]. (2020). Available online at: https://cpr.heart.org/en/resources/historyof-cpr (accessed March 31, 2020).

2. LLC P. When did the new CPR start Pro Trainings LLC. (2017). Available online at: https://www.procpr.org/blog/misc/history-of-cpr (accessed March 31, 2020).

3. American Association for the Advancement of Science. DNR Given Up as a Loser, Citizen Support Lacking. Science. (1979) 204:924. doi: 10.1126/science.204.4396.924

4. The ethics of CPR vs. DNR. Maine Nurse. (1989) 75:5.

5. Lund M. Conflicts in ethics. Is DNR the right choice? Geriatr Nurs. (1990) 11:291-2. doi: 10.1016/S0197-4572(05)80298-8

6. Merckel L. DNR-a code of ethics. Health care. (1985) 27:14-7.

7. Fosbinder J. “Code DNR” for the incompetent terminally ill. J Ten Med Assoc. (1980) 73:663-6.

8. Levin DL, Levin NR. DNR: an objectionable form of euthanasia. Univ Cincinnati Law Rev. (1980) 49:567-79.

9. Hileli I, Weyl Ben Arush M, Hakim F, Postovsky S. Association between religious and socio-economic background of parents of children with solid tumors and DNR orders. Pediatr Blood Can. (2014) 61:2658. doi: $10.1002 /$ pbc. 24712

10. Jaul E, Zabari Y, Brodsky J. Spiritual background and its association with the medical decision of, DNR at terminal life stages. Archiv Gerontol Geriatr. (2014) 58:25-9. doi: 10.1016/j.archger.2013.08.004

11. Arai T, Namiki A, Amaha K, Shigematsu A, Suzuki M, Kimura S, et al. [Response to a questionnaire on DNR-order from 307 trustee members of Japanese medical societies]. Masui Japan J Anesthesiol. (1994) 43:600-11.

12. Vranick J, Sanghavi D, Torp KD, Stanton M. Do not resuscitate. In: StatPearls [Internet]. Treasure Island, FL: StatPearls Publishing (2021).

13. Fu PK, Tung YC, Wang CY, Hwang SF, Lin SP, Hsu CY, et al. Early and late do-not-resuscitate (DNR) decisions in patients with terminal COPD: a retrospective study in the last year of life. Int J Chron Obstruct Pulmon Dis. (2018) 13:2447-54. doi: 10.2147/COPD.S168049

14. Cherniack EP. Increasing use of DNR orders in the elderly worldwide: whose choice is it? J Med Ethics. (2002) 28:303-7. doi: 10.1136/jme.28.5.303

15. Burns JP, Truog RD. The DNR Order after 40 Years. N Eng J Med. (2016) 375:504-6. doi: 10.1056/NEJMp1605597

16. Higginson J, Lang KR, Ransom H, Parker C, Ledoux M, Hester DM, et al. When a mother changes her mind about a DNR. Pediatrics. (2018) 142. doi: 10.1542/peds.2017-2946

17. Vallabhajosyula S, Ingram C. In high-risk ICU patients, early palliative care consultation increased transition to DNR/DNI status. Ann Int Med. (2020) 172:JC30. doi: 10.7326/ACPJ202003170-030

18. Walkey AJ, Weinberg J, Wiener RS, Cooke CR, Lindenauer PK. Association of do-not-resuscitate orders and hospital mortality rate among patients with pneumonia. JAMA Int Med. (2016) 176:97-104. doi: 10.1001/jamainternmed.2015.6324

19. Zweig SC, Kruse RL, Binder EF, Szafara KL, Mehr DR. Effect of do-not-resuscitate orders on hospitalization of nursing home residents evaluated for lower respiratory infections. J Am Geriatr Soc. (2004) 52:518. doi: 10.1111/j.1532-5415.2004.52010.x

20. WHO. Emergencies Preparedness. (2010). Available online at: https://www. livescience.com/worst-epidemics-and-pandemics-in-history.html (accessed March 31, 2020).

21. Eisenberg J. R0: How Scientists Quantify the Intensity of an Outbreak Like Coronavirus and Its Pandemic Potential: University of Michigan. (2020) Available online at: https://sph.umich.edu/pursuit/2020posts/how-scientistsquantify-outbreaks.html (accessed March 31, 2020).

22. United Kingdom RC. CPR in H1N1. (2009). Available online at: https://www. resus.org.uk/archive/archived-cpr-information/cpr-and-pandemic-h1n12009-influenza-in-healthcare-settings/ (accessed March 31, 2020).

23. Brooks M. AHA Guidance for CPR, Emergency CV Care Amid COVID-19. (2020). Available online at: https://www.medscape.com/viewarticle/927389 (accessed March 31, 2020).

24. Vaidya A. New Guidelines for Hospitals Providing CPR to COVID-19 Patients. (2020). Available online at: https://www.beckershospitalreview.com/patient- safety-outcomes/new-guidelines-for-hospitals-providing-cpr-to-covid-19patients.html (accessed March 31, 2020).

25. Emanuel EJ, Persad G, Upshur R, Thome B, Parker M, Glickman A, et al. Fair allocation of scarce medical resources in the time of Covid-19. N Eng J Med. (2020) 382:2049-55. doi: 10.1056/NEJMsb2005114

26. Post W. Hospitals Consider Universal Do-Not-Resuscitate Orders for Coronavirus Patients: Washington Post. (2020). Available online at: https:// www.washingtonpost.com/health/2020/03/25/coronavirus-patients-do-notresucitate/

27. Curtis JR, Kross EK, Stapleton RD. The importance of addressing advance care planning and decisions about do-not-resuscitate orders during novel coronavirus 2019 (COVID-19). JAMA. (2020). doi: 10.1001/jama.2020.4894

28. Jayson T, Neagle KW. What are the Chances a Hospitalized Patient Will Survive In-Hospital Arrest? (2010) Available online at: https://www.thehospitalist.org/hospitalist/article/124220/what-are-chances-hospitalizedpatient-will-survive-hospital-arrest (accessed March 31, 2020).

29. Nurse C. Code Status Orders at Valley Hospital Streamline RN Responses. (2009). Available online at: https://www.nurse.com/blog/2009/11/02/codestatus-orders-at-valley-hospital-streamline-rn-responses/ (accessed March 31, 2020).

30. Chan PS, Berg RA, Nadkarni VM. Code blue during the COVID-19 pandemic. Cir Cardiov Quali Outcomes. (2020). doi: 10.1161/CIRCOUTCOMES.120.006779

31. Krutli P, Rosemann T, Tornblom KY, Smieszek T. How to fairly allocate scarce medical resources: ethical argumentation under scrutiny by health professionals and lay people. PLoS ONE. (2016) 11:e0159086. doi: 10.1371/journal.pone.0159086

32. Rosenbaum L. Facing Covid-19 in italy - ethics, logistics, and therapeutics on the epidemic's front line. N Eng J Med. (2020). doi: 10.1056/NEJMp2005492

33. Pettersson M, Hedstrom M, Hoglund AT. Ethical competence in DNR decisions -a qualitative study of Swedish physicians and nurses working in hematology and oncology care. BMC Med Ethics. (2018) 19:63. doi: 10.1186/s12910-018-0300-7

34. Brovman EY, Walsh EC, Burton BN, Kuo CE, Lindvall C, Gabriel $\mathrm{RA}$, et al. Postoperative outcomes in patients with a do-not-resuscitate (DNR) order undergoing elective procedures. J Clin. Anes. (2018) 48:81-8. doi: 10.1016/j.jclinane.2018.05.007

35. Shamieh O, Richardson K, Abdel-Razeq H, Harding R, Sullivan R, Mansour A. COVID-19-Impact on DNR orders in the largest cancer center in Jordan. J Pain Symptom Manag. (2020). doi: 10.1016/j.jpainsymman.2020. 04.023

36. Yin E. Hippocrates Oath. (2010). Available online at: https://www.bu.edu/ arion/files/2010/03/Arenas_05Feb2010_Layout-3.pdf (accessed March 31, 2020).

37. Plunkett AJ. COVID-19: Hospitals Should Consider CoP Carefully Before Deciding on DNR Policy. (2020). Available online at: https://www.psqh.com/ news/covid-19-hospitals-should-consider-cop-carefully-before-decidingon-dnr-policy/ (accessed March 31, 2020).

38. Zhenyu Li JG, Yang M, Feng J, Qiao M, Jiang R, Bi J, et al. Vicarious traumatization in the general public, members, and non-members of medical teams aiding in COVID-19 control. Brain Behav Immun. (2020) 88:916-9. doi: 10.1016/j.bbi.2020.03.007

39. Truog RD, Mitchell C, Daley GQ. The toughest triage - allocating ventilators in a pandemic. N Engl J Med. (2020) 382:1973-5 doi: 10.1056/NEJMp2005689

40. Ferraresi M. A Coronavirus Cautionary Tale From Italy: Don't Do What We Did. Boston, MA: Boston Globe (2020).

41. Gillon R. Medical ethics: four principles plus attention to scope. Bmj. (1994) 309:184. doi: 10.1136/bmj.309.6948.184

42. Pettersson M, Hoglund AT, Hedstrom M. Perspectives on the DNR decision process: a survey of nurses and physicians in hematology and oncology. PLoS ONE. (2018) 13:e0206550. doi: 10.1371/journal.pone.0206550

43. Breu AC, Herzig SJ. Differentiating DNI from DNR: combating code status conflation. J Hosp Med. (2014) 9:669-70. doi: 10.1002/jhm.2234

44. Cauley CE, El-Jawahri AR, Jacobsen JC, Udelsman BV, Jackson VA, Temel JS, et al. DNR, DNI, and DNO? J Palli Med. (2019). doi: 10.1089/jpm.2019.0486

45. Igoe S, Cascella S, Stockdale K. Ethics in the OR: DNR and patient autonomy. Nurs Manag. (1993) 24:112A. doi: 10.1097/00006247-19930900000018 
46. Huang CH, Hu WY, Chiu TY, Chen CY. The practicalities of terminally ill patients signing their own DNR orders-a study in Taiwan. J Med Ethics. (2008) 34:336-40. doi: 10.1136/jme.2007.020735

47. Headley JA. The DNR decision-Part II. Ethical principles and application. Dim Oncol Nurs. (1991) 5:34-7.

48. Gillon R. Justice and medical ethics. Br Med J. (1985) 291:2012. doi: 10.1136/bmj.291.6489.201

49. Vergano M, Bertolini G, Giannini A, Gristina GR, Livigni S, Mistraletti $\mathrm{G}$, et al. Clinical ethics recommendations for the allocation of intensive care treatments in exceptional, resource-limited circumstances: the Italian perspective during the COVID-19 epidemic. Crit Care. (2020) 24:201-2. doi: 10.1186/s13054-020-02891-w

50. Ferioli M, Cisternino C, Leo V, Pisani L, Palange P, Nava S. Protecting healthcare workers from SARS-CoV-2 infection: practical indications. Euro Resp Rev. (2020) 29:200068. doi: 10.1183/16000617.0068-2020

51. White DB, Angus DC. A proposed lottery system to allocate scarce COVID-19 medications. JAMA. (2020). doi: 10.1001/jama.2020.11464

52. Kinsinger FS. Beneficence and the professional's moral imperative. J Chirop Hum. (2009) 16:44-6. doi: 10.1016/j.echu.2010.02.006

53. Snider GL. The do-not-resuscitate order: ethical and legal imperative or medical decision? Am Rev Resp Dis. (1991) 143:665-74. doi: 10.1164/ajrccm/143.3.665

54. Lipsky MS. Indications for DNR orders: a review. Res Staff Phys. (1986) 32:4751.

55. Edwards BS. Does the DNR patient belong in the ICU? Crit Care Nurs Clin North Am. (1990) 2:473-80. doi: 10.1016/S0899-5885(18) 30807-4

56. Simmons-Duffin S. States Get Creative to Find and Deploy More Health Workers In COVID-19 Fight. (2020) Available online at: https://www.npr.org/ sections/health-shots/2020/03/25/820706226/states-get-creative-to-findand-deploy-more-health-workers-in-covid-19-fight
57. Lederberg MS. Doctors in limbo: the United States 'DNR' debate. Psycho Oncol. (1997) 6:321-8. doi: 10.1002/(SICI)10991611(199712)6:4\&<321::AID-PON289\&>3.0.CO;2-\#

58. Junod Perron N, Morabia A, De Torrente A. Evaluation of do not resuscitate orders (DNR) in a swiss community hospital. J Med Ethics. (2002) 28:3647. doi: 10.1136/jme.28.6.364

59. Yuen JK, Reid MC, Fetters MD. Hospital do-not-resuscitate orders: why they have failed and how to fix them. J Gen Int Med. (2011) 26:7917. doi: 10.1007/s11606-011-1632-x

60. Martin RD, Cohen MA, Weiss Roberts L, Batista SM, Hicks D, Bourgeois J. DNR versus DNT: clinical implications of a conceptual ambiguity: a case analysis. Psychosomatics. (2007) 48:10-5. doi: 10.1176/appi.psy. 48.1.10

61. Ciulla MR, Salisbury SR, McSherry E. Quality assurance in DNR (do not resuscitate) decisions-the role of chaplaincy: a case report and a 92 patient group study. J Health Care Chapl. (1988) 2:5780. doi: 10.1300/J080v02n01_07

62. Research TECfFa. The Jurisprudential Developments Due to the COVID-19 Pandemic. Dublin: Islamic Jurisprudence for Muslims in Europe (2020).

Conflict of Interest: The authors declare that the research was conducted in the absence of any commercial or financial relationships that could be construed as a potential conflict of interest.

Copyright (C) 2021 Sultan, Mansour, Shamieh, Al-Tabba' and Al-Hussaini. This is an open-access article distributed under the terms of the Creative Commons Attribution License (CC BY). The use, distribution or reproduction in other forums is permitted, provided the original author(s) and the copyright owner(s) are credited and that the original publication in this journal is cited, in accordance with accepted academic practice. No use, distribution or reproduction is permitted which does not comply with these terms. 